\title{
Sleep disordered breathing and the outcome of stroke
}

\section{G J Gibson}

\section{Patients with OSA not only have an increased risk of stroke, but also a higher mortality and greater disability after stroke}

nterest in abnormal breathing after stroke has a long history dating back at least to the observations of John Cheyne in 1818. ${ }^{1}$ In recent years this interest has been reawakened by a number of publications on the relations between sleep disordered breathing (SDB) and stroke. These studies have been of two main types-those investigating the possible increased risk of stroke in individuals with obstructive sleep apnoea (OSA) and those reporting a high prevalence of SDB after stroke and its possible effects on residual disability and mortality. Unravelling the direction of causality-that is, whether OSA causes stroke or stroke causes OSA-has proved challenging. ${ }^{2-5}$

\section{OSA AND RISK OF STROKE}

Most of the evidence on the risk of stroke associated with OSA is circumstantial and is based on case-control studies in which a history of snoring, with or without other features suggestive of OSA, is compared in patients with stroke and matched controls. ${ }^{6-11}$ Such studies lack objective confirmation of pre-stroke OSA, are critically dependent on the validity of the control population, and are subject to recall bias. Moreover, most studies have included subjects who had previously had a stroke where, inevitably, the direction of causality is uncertain. In studies where account has been taken of potential confounding factors such as obesity, smoking and hypertension, the estimated risk of stroke is reduced. Of the possible "confounders", hypertension is of particular relevance as the contribution of OSA to systemic hypertension has been demonstrated beyond reasonable doubt and clearly it offers a potential causal link with stroke. Even after statistical adjustment for hypertension, however, several studies still support an association between OSA and stroke. Various alternative mechanisms related to demonstrated abnormalities in patients with OSA have been suggested. These include abnormal cerebral haemodynamics, ${ }^{12}$ increased platelet aggregability, ${ }^{13}$ increased fibrinogen concentration, ${ }^{14}$ increased blood viscosity, ${ }^{15}$ and abnormal vascular endothelial function. ${ }^{16}$ On the other hand, snoring alone, without other features of OSA, appears to carry little if any excess risk. ${ }^{17}$

Although the weight of evidence favouring OSA as an independent risk factor for stroke is suggestive, cross sectional studies can never give a definitive result. Confirmation awaits the full publication of large prospective studies which are currently in progress. Preliminary data from one such study, published so far only as an abstract, ${ }^{18}$ support the conclusion that OSA is a risk factor for the development of stroke or transient ischaemic attack (TIA), independently of sex, body mass index, diabetes, and hypertension.

\section{SDB AFTER STROKE}

Complementing these studies of the risk of stroke associated with OSA, several others have shown a high prevalence of SDB after stroke. ${ }^{19-26}$ Most have been observational with no control group, an important omission in light of the high frequency of apnoeas and hypopnoeas in apparently healthy elderly subjects. ${ }^{27}$ However, three studies which included small age matched control groups ${ }^{20} 2128$ each showed a significantly higher apnoea-hypopnoea index (AHI) in the stroke patients. On the other hand, a recent study ${ }^{29}$ comparing patients with TIA and individually matched controls showed no difference in AHI, although the frequency of nocturnal desaturation $>4 \%$ was greater in the patient group. Two reports of sequential sleep studies after stroke showed a significant reduction in AHI 2-3 months later, ${ }^{23}{ }^{24}$ although in a third study, ${ }^{30}$ based on oximetry only, there was no change in the desaturation index in stroke survivors restudied 3 months after the event.

Are these observations merely of curiosity value or might SDB adversely affect the outcome of stroke? In the current issue of Thorax Turkington et al ${ }^{31}$ add further evidence that this may indeed be the case. In an earlier study of a small number of patients Good et $a l^{19}$ showed that a higher nocturnal desaturation index was associated with greater mortality and more severe disability in survivors 12 months after the event. More recently, Iranzo et $a l^{32}$ studied patients during the first night after a stroke and found that a high AHI was associated with early neurological deterioration, although this did not correlate with disability 6 months later. The study by Turkington et al has the advantage of including a larger and less selected population, which is broadly typical of patients with stroke admitted to hospital in the UK; they were generally older and more disabled than those included in many of the previous studies performed in neurological or rehabilitation units. Turkington et al showed clear relations between SDB in the first 24 hours after stroke and length of hospital stay, mortality, and greater dependency of survivors 6 months later. Another recent study ${ }^{26}$ of younger patients in a rehabilitation unit also reported that SDB 6 weeks after a stroke was independently associated with longer hospital stay and greater long term functional impairment.

\section{POSSIBLE MECHANISMS}

Why then might subjects with OSA fare particularly badly after stroke? Several of the pathophysiological features accompanying OSA have also been associated with an adverse outcome in stroke populations. These include:

- Large fluctuations of blood pressure and the consequent effects on cerebral blood flow: in OSA repeated elevation of blood pressure, sometimes to an alarming degree, is seen at the termination of each apnoea. ${ }^{33}$ In stroke patients a greater variation in blood pressure correlates with both increased mortality and greater dependency. ${ }^{34}$

- Baroceptor dysfunction has been reported in $\mathrm{OSA}^{35}$ and impaired cardiac baroceptor sensitivity is associated with higher mortality after stroke. ${ }^{36}$

- Recurrent hypoxaemia associated with frequent apnoeas is another obvious candidate. This might have a critical effect on the "ischaemic penumbra" surrounding the infarcted brain and might result in extension of the neurological damage.

- Alternating hypoxaemia and reoxygenation accompanying OSA is associated with increased release of superoxides from neutrophils ${ }^{37}$ which might have an adverse effect after

Abbreviations: $A H I$, apnoea-hypopnoea index; OSA, obstructive sleep apnoea; SDB, sleep disordered breathing; TIA, transient ischaemic attack 
stroke in light of evidence from animal stroke models. ${ }^{38}$

- Inflammatory and proinflammatory markers and mediators such as $C$ reactive protein $^{39}$ and adhesion molecules ${ }^{40}$ are increased in OSA while, in stroke, inflammatory changes are increasingly recognised as possibly contributing to injury of vulnerable brain tissue. ${ }^{41}$

Clearly, therefore, there are many similarities between the pathophysiological changes which accompany OSA and factors which influence the outcome of stroke. Further work will be required to tease out which of the above are likely to be most relevant to the associations shown by Turkington et al. ${ }^{31}$

Most of the features associated with more severe SDB after stroke are consistent with pre-existing OSA. These include a history of snoring ${ }^{22} 42$ or sleepiness $^{28}{ }^{30}$ and greater body mass index ${ }^{21} 2225$ and neck circumference. ${ }^{22} 25$ Also relevant is an earlier case-control study $^{43}$ which showed a clear doseresponse relationship between the reported severity of pre-stroke snoring and mortality 6 months after a stroke. On the other hand, there is little apparent relation between SDB and the characteristics of a recent stroke such as its clinical severity ${ }^{24-2630}$ or location, ${ }^{232632}$ or the extent of acute changes visible on CT scanning. ${ }^{44}$ SDB is, however, more severe in patients with the lacunar syndrome ${ }^{24} 30$ which is closely related to hypertension, and in those with CT evidence of chronic cerebrovascular disease. ${ }^{44}$

Taken together, a unifying hypothesis arising from these various studies would be that patients with pre-existing OSA have an increased risk, not only of developing stroke but also of an adverse outcome in terms of both mortality and disability. Such individuals may be more likely to show exaggerated SDB after a stroke and a consequent poor outcome.

\section{CLINICAL IMPLICATIONS}

Are these findings merely of theoretical interest or might they have practical relevance? The most obvious therapeutic implication relates to the potential value of treating OSA after a stroke with continuous positive airway pressure (CPAP). Although one study reported that some younger patients during rehabilitation after stroke will tolerate $\mathrm{CPAP}^{45}$ our experience, like that of others studying a more representative older population, ${ }^{46}{ }^{47}$ has been more pessimistic. If CPAP is to influence the outcome of stroke by limiting ischaemic damage to the vulnerable areas of brain in the "penumbra", it seems likely that its optimal timing would be very soon after the event. However, the practicalities of introducing such unfamiliar treatment to elderly, disabled, and sometimes confused patients in an acute hospital ward or stroke unit are such that the widespread applicability of CPAP after a stroke is unlikely. It may, nonetheless, have a role in selected individuals. Hui et $a l^{47}$ found that the small minority of patients who tolerated CPAP shortly after a stroke had symptoms suggesting pre-existing OSA. This conclusion concurs with studies of patients with OSA in whom compliance with CPAP is better in those with more severe symptoms, particularly daytime sleepiness. $^{48}$ In practice, of course, stroke patients with features of preexisting OSA may be the very ones to target for CPAP therapy if, as suggested above, the adverse prognosis associated with SDB following stroke is due mainly to pre-stroke OSA.

\section{ACKNOWLEDGEMENT}

The author thanks Professor G A Ford for helpful discussion.

Thorax 2004;59:361-363.

doi: $10.1136 /$ thx.2003.020040

Correspondence to: Professor G J Gibson, Department of Respiratory Medicine, Freeman Hospital, Newcastle upon Tyne NE7 7DN, UK; g.j.gibson@ncl.ac.uk

\section{REFERENCES}

1 Cheyne J. A case of apoplexy in which the fleshy part of the heart was converted into fat. Dublin Hospital Reports 1818;2:216-23.

2 Harbison JA, Gibson GJ. Snoring, sleep apnoea and stroke: chicken or scrambled egg? Q J Med 2000;93:647-54

3 Mohsenin V. Sleep-related breathing disorders and risk of stroke. Stroke 2001;32:1271-8.

4 Neau JP, Paquereau J, Meurice JC, et al. Stroke and sleep apnoea: cause or consequence? Sleep Med Rev 2002;6:457-69.

5 Yaggi H, Mohsenin V. Sleep-disordered breathing and stroke. Clin Chest Med 2003;24:223-37.

6 Partinen M, Palomaki H. Snoring and cerebral infarction. Lancet 1985;ii:1325-6.

7 Koskenvuo M, Kaprio J, Telakivi T, et al. Snoring as a risk factor for ischaemic heart disease and stroke in men. BMJ 1987;294:16-9.

8 Spriggs DA, French JM, Murdy JM, et al. Historical risk factors for stroke: a case control study. Age Ageing 1990;19:280-7.

9 Palomaki H. Snoring and the risk of ischemic brain infarction. Stroke 1991;22:1021-5.

10 Smirne S, Palazzi S, Zucconi M, et al. Habitual snoring as a risk factor for acute vascular disease. Eur Respir J 1993;6:1357-61.

11 Neau JP, Meurice JC, Paquereau J, et al. Habitual snoring as a risk factor for brain infarction. Acto Neurol Scand 1995;92:63-8.

12 Franklin KA. Cerebral haemodynamics in obstructive sleep apnoea and Cheyne-Stokes respiration. Sleep Med Rev 2002:6:429-41.

13 Sanner BM, Konermann M, Tepel M, et al. Platelet function in patients with obstructive sleep apnoea syndrome. Eur Respir $J$ 2000;16:648-52.

14 Wessendorf TE, Thilmann AF, Wang YM, et al. Fibrinogen levels and obstructive sleep apnea in ischemic stroke. Am J Respir Crit Care Med 2000; 162:2039-42.

15 Nobili L, Schiavi G, Bozano E, et al. Morning increase of whole blood viscosity in obstructive sleep apnea syndrome. Clin Hemorheol Microcirc 2000;22:21-7.

16 Kato M, Roberts-Thompson P, Phillips B, et al. Impairment of endothelium-dependent vasodilation of resistance vessels in patients with obstructive sleep apnea. Circulation 2000; 102:2607-10.

17 Davies DP, Rodgers H, Walshaw D, et al. Snoring, daytime sleepiness and stroke: a casecontrol study of first-ever stroke. J Sleep Res 2003; 12:313-8

18 Yaggi K, Kernan W, Mohsenin V. The association between obstructive sleep apnea and stroke. Am J Respir Crit Care Med 2003;167:A173.

19 Good DC, Henkle JQ, Gelber D, et al. Sleep disordered breathing and poor functional outcome after stroke. Stroke 1996;27:252-9.

20 Dyken ME, Somers VK, Yamada T, et al. Investigating the relationship between stroke and obstructive sleep apnea. Stroke 1996;27:401-7.

21 Bassetti C, Aldrich MS. Sleep apnea in acute cerebrovascular diseases: final report on 128 patients. Sleep 1999;22:217-23.

22 Wessendorf TE, Teschler $\mathrm{H}$, Wang YM, et al. Sleep-disordered breathing among patients with first-ever stroke. J Neurol 2000;247:41-7.

23 Parra O, Arboix A, Bechich S, et al. Time course of sleep-related breathing disorders in first-ever stroke or transient ischemic attack. Am J Respir Crit Care Med 2000; 161:375-80.

24 Harbison J, Ford GA, James OFW, et al. Sleepdisordered breathing following acute stroke. Q J Med 2002;95:741-7.

25 Turkington PM, Bamford J, Wanklyn P, et al Prevalence and predictors of upper airway obstruction in the first 24 hours after acute stroke. Stroke 2002;33:2037-42.

26 Kaneko Y, Hajek VE, Zivanovic V, et al. Relationship of sleep apnea to functional capacity and length of hospitalization following stroke. Sleep 2003;26:293-7.

27 Ancoli-Israel S, Kripke DF, Klauber MR, et al. Sleep-disordered breathing in communitydwelling elderly. Sleep 1991;14:486-95.

28 Nasr-Wyler A, Bouillanne O, Lalhou A, et al. Syndrome d'apnees du sommeil et accident vasculaire cerebral dans une population agee. Rev Neurol (Paris) 1999; 155:1057-62.

29 McArdle N, Riha RL, Vennelle M, et al. Sleepdisordered breathing as a risk factor for cerebrovascular disease: a case-control study in patients with transient ischaemic attacks. Stroke 2003;34:2916-21.

30 Lawrence E, Dundas R, Higgens S, et al. The natural history and associations of sleep disordered breathing in first ever stroke. Int $J$ Clin Pract 2001;55:584-8.

31 Turkington PM, Allgar V, Bamford J, et al. Effect of upper airway obstruction in acute stroke on functional outcome at 6 months. Thorax 2004;59:367-71

32 Iranzo A, Santamaria J, Berenguer J, et al. Prevalence and clinical importance of sleep apnea in the first night after cerebral infarction. Neurology 2002;58:911-6.

33 Shepard JW. Gas exchange and hemodynamics during sleep. Med Clin North Am 1985;69:1234-64.

34 Dawson SL, Manktelow BN, Robinson TG, et al. Which parameters of beat-to-beat blood pressure and variability best predict early outcome after acute ischemic stroke? Stroke 2000;31:463-8.

35 Belozeroff V, Berry RB, Khoo MC. Model-based assessment of autonomic control in obstructive sleep apnea syndrome. Sleep 2003;26:65-73.

36 Robinson TG, Dawson SL, Eames PJ, et al. Cardiac baroreceptor sensitivity predicts longterm outcome after acute ischemic stroke. Stroke 2003;34:705-12.

37 Schulz R, Mahmoudi S, Hattar K, et al. Enhanced release of superoxide from polymorphonuclear neutrophils in obstructive sleep apnea. Am J Respir Crit Care Med 2000; 162:566-70.

38 Chan PH. Reactive oxygen radicals in signaling and damage in the ischemic brain. J Cereb Blood Flow Metab 2001;21:2-14

39 Shamsuzzaman ASM, Winnicki M, Lanfranchi P, et al. Elevated C-reactive protein in patients with obstructive sleep apnea. Circulation 2002; 105:2462-4. 
40 Dyugovskaya L, Lavie P, Lavie L. Increased adhesion molecules expression and production of reactive oxygen species in leukocytes of sleep apnea patients. Am J Respir Crit Care Med 2002; 165:934-9

41 del Zoppo G, Ginis I, Hallenbeck JM, et al. Inflammation and stroke: putative role for cytokines, adhesion molecules and iNOS in brain response to ischemia. Brain Pathol 2000;10:95-112.

42 Cherkassky T, Oksenberg A, Froom P, et al. Sleep-related breathing disorders and rehabilitation outcome of stroke patients. A prospective study. Am J Phys Med Rehabil 2003;82:452-5.

43 Spriggs DA, French JM, Murdy JM, et al. Snoring increases the risk of stroke and adversely affects prognosis. Q J Med 1992;83:555-62.

44 Harbison J, Gibson GJ, Birchall D, et al. White matter disease and sleep-disordered breathing after acute stroke. Neurology 2003:61:959-63.

45 Wessendorf TE, Wang YM, Thilmann AF, et al. Treatment of obstructive sleep apnoea with nasal continuous positive airway pressure in stroke. Eur Respir J 2001;18:623-9.

\section{$\alpha_{1}$-Antitrypsin: more than just deficiency}

\section{R A Stockley}

\section{Abnormal levels of $\alpha_{1}$-antitrypsin represent a syndrome of clinical disease entities, some relating to a deficiency while others reflect an overload}

46 Sandberg O, Franklin KA, Bucht G, et al. Nasal continuous positive airway pressure in stroke patients with sleep apnoea: a randomised treatment study. Eur Respir J 2001; 18:630-4.

47 Hui DSC, Choy DKL, Wong LKS, et al. Prevalence of sleep-disordered breathing and continuous positive airway pressure compliance. Results in Chinese patients with first-ever ischemic stroke. Chest 2002;122:852-60.

48 McArdle N, Devereux G, Heidarnejad H, et al. Long-term use of CPAP therapy for sleep apnea/ hypopnea syndrome. Am J Respir Crit Care Med 1999:159:1108-14.

The role of serum deficiency in the emphysematous process led to the introduction of augmentation therapy with purified $\alpha_{1}$-antitrypsin in 1988. This was a logical approach leading to an increase in the serum and hence the lung concentrations of $\alpha_{1}$-antitrypsin to "protective" levels. These studies resulted in "deficiency" being a pathological problem associated with lung disease and the outcome was that $\alpha_{1}$-antitrypsin deficiency became largely the domain of respiratory medicine.

However, in 1969 Sharp and colleagues recognised that subjects with the

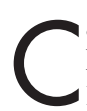
arl-Bertil Laurell (1919-2001) was head of the Clinical Chemistry Department at Malmö General Hospital, University of Lund, Sweden (1954-84) and continued working in the department until his death in 2001. He had an interest in the initial studies of protein biochemistry, and his early paper on electrophoresis studies of serum proteins led to the discovery of subjects with deficient bands in the $\alpha_{1}$ globulin region. ${ }^{1}$ This region showed the greatest inhibition of trypsin, and the major protein within the band became known as $\alpha_{1}$-antitrypsin. Having identified several subjects with a weak $\alpha_{1}$ band seen on paper electrophoresis, Laurell and his research fellow Eriksson investigated the patients further. Three of the original five patients had severe early onset pulmonary emphysema suggesting a cause and effect. ${ }^{1}$ For many years research focused on understanding the role of this protein in the pathogenesis of emphysema. Enzymes inhibited by $\alpha_{1}$-antitrypsin were shown to be capable of producing many of the pathological features of COPD including emphysema, mucous gland hyperplasia, and mucus secretion. Because most of the $\alpha_{1}$-antitrypsin in the lung is derived from the circulation by diffusion, low serum levels were associated with low lung concentrations. This resulted in insufficient amounts of $\alpha_{1}$-antitrypsin in the lung to protect the tissues from damage by the enzymes-predominantly neutrophil elastase-normally controlled by this inhibitor (the proteinase antiproteinase theory of emphysema). ${ }^{2}$

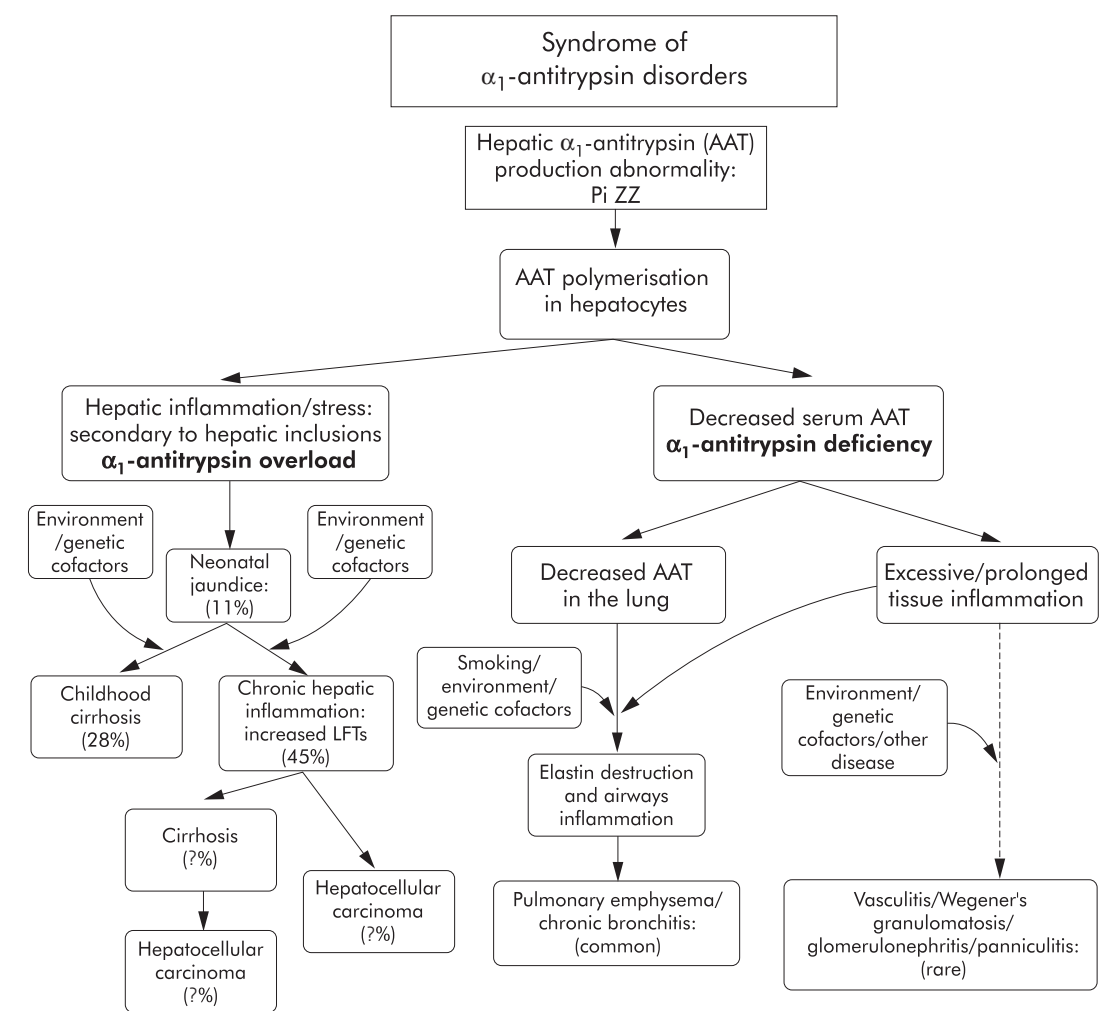

Figure 1 Hepatic polymerisation of the $\alpha_{1}$-antitrypsin ( $\mathrm{Pi}$ ZZ) protein results in both hepatocyte inclusions and decreased serum concentration. The low serum level is reflected in a low lung level of $\alpha_{1}$-antitrypsin which is insufficient to protect the tissue from inflammation generated, for example, by cigarette smoking. Prolonged inflammation, together with as yet unknown environmental or genetic factors, leads to airway and parenchymal damage resulting in lung disease. The inflammatory process of vasculitides and panniculitis may also represent a failure to modulate inflammation as a result of low serum and tissue levels of $\alpha_{1}$-antitrypsin, in combination with other cofactors yet to be determined. Within the hepatocytes the $\alpha_{1}$-antitrypsin polymers cause inflammation that probably plays a role in the transient neonatal jaundice seen in $11 \%$ of individuals with $\mathrm{Pi} Z \mathrm{ZZ}$. In most this resolves, but in others childhood cirrhosis develops or the hepatic inflammation persists. Again, as yet undefined genetic or environmental factors may play a role in this persistent inflammation. With time, adult cirrhosis and hepatocellular carcinoma may occur, although the true incidence has yet to be determined. 
commonest (Pi ZZ) serum deficiency had a relatively high frequency of liver disorders, including neonatal jaundice and cirrhosis. ${ }^{3}$ Subjects were shown to have hepatocyte accumulation of $\alpha_{1}$ antitrypsin which is thought to be the reason for hepatocyte damage. Thus, unlike the lung disease, the liver disease became recognised as an "overload" problem. Accumulation of $\alpha_{1}$-antitryp$\sin$ is the result of protein polymerisation, and the understanding of this process led to strategies to facilitate secretion and thereby protect the liver. ${ }^{4}$

With growing interest in the genetic nature of diseases and the clinical disorders associated with $\alpha_{1}$-antitrypsin abnormalities, many countries developed national registries. This has resulted in the discovery of other clinical conditions that are more frequent in individuals with Pi ZZ antitrypsin, including vasculitis, ${ }^{5}$ Wegener's granulomatosis, glomerulonephritis, ${ }^{7}$ and panniculitis. ${ }^{8}$ Thus, the condition is associated with many clinical disease entities and is more representative of a syndrome. These aspects are outlined in fig 1.
Although Pi ZZ has classically been referred to as a "deficiency", this does not explain all the facets of the diseases. Some relate to "deficiency" while others clearly reflect an "overload". Much has been learned since $\alpha_{1}$-antitrypsin "deficiency" was recognised by Laurell 40 years ago. This syndrome of $\alpha_{1^{-}}$ antrypsin disorders, and particularly the disparity between "deficiency" and "overload", has brought researchers together from many fields-including pulmonary, genetics, hepatology, nephrology, dermatology and rheumatology - to extend the understanding of $\alpha_{1}$-antitrypsin. Collaborative efforts are leading to strategies that both reduce the "overload" and overcome the "deficiency" which may resolve the many faceted nature of this genetic defect.

Thorax 2004;59:363-364.

doi: $10.1136 /$ thx.2004.023572

Correspondence to: Professor R A Stockley, Department of Medicine, Queen Elizabeth Hospital, Edgbaston, Birmingham B15 2TH, UK; r.a.stockley@bham.ac.uk

The author is a member of AIR (The Alpha International Registry). This is based on an original concept suggested and refined by John Humphries.

\section{REFERENCES}

1 Laurell C-B, Eriksson S. The electrophoretic $\alpha$-1globulin pattern of serum in $\alpha-1$ antitrypsin deficiency. Scand J Clin Lab Invest 1963;15:132-40

2 Gadek JE, Fells GA, Zimmerman RL, et al. Antielastases of the human alveolar structures. Implications for the protease-antiprotease theory of emphysema. J Clin Invest 1981;68:889-98.

3 Sharp HL, Bridges RA, Krivitt W, et al. Cirrhosis associated with alpha-1-antitrypsin deficiency: a previously unrecognized inherited disorder. J Lab previously unrecognized in

4 Teckman JH, Qu D, Perlmutter DH. Molecular pathogenesis of liver disease in alpha-1-antitrypsin deficiency. Hepatology 1996;24:1504-16.

5 Donogue DJ, Guickian M, Blundell G, et al. Alpha-1-protease inhibitor and pulmonary haemorrhage in systemic vasculitis. Adv Exp Med Biol 1993;336:331-5.

6 Elzouki ANY, Segelmark M, Wieslander J, et al. Strong link between the alpha-1-antitrypsin PiZ allele and Wegener's granulomatosis. J Intern Med 1994;236:543-8.

7 Davis ID, Burke B, Freese D, et al. The pathologic spectrum of the nephropathy associated with alpha-1-antitrypsin deficiency. Hum Pathol 1992;23:57-62.

8 Rubinstein HM, Jaffer AM, Kudrna JC, et al. Alpha-1-antitrypsin deficiency with severe panniculitis: report of two cases. Ann Intern Med 1977;86:742-4

\section{4 update of BTS pneumonia guidelines: what's new?}

\section{J T Macfarlane, D Boldy}

\section{An update of the BTS guidelines for the management of community acquired pneumonia in adults}

$\mathrm{T}$

he BTS guidelines for the management of adult community acquired pneumonia (CAP), published in December 2001, assessed relevant evidence published up to $2000 .^{1}$ An update summarising more recent available evidence up to 2003 has just been published on the BTS website (www.britthoracic.org.uk/guidelines) using an identical search assessment and appraisal system. Minor additions or changes have been made in the sections on aetiology (related to nursing home acquired pneumonia), general investigations (use of $\mathrm{C}$ reactive protein and oximetry), general management, and vaccination strategies. The more important changes have been in the recommendations for the microbiological investigation of CAP, severity assessment, discharge planning, and antibiotics. At present these guidelines do not include information on severe acute respiratory syndrome (SARS), for which an updated specific guideline is available on the BTS website to help clinicians with case definition and management and will shortly be published in the Journal of Infection.

\section{IMPORTANT CHANGES TO 2001 BTS GUIDELINES ON CAP MANAGEMENT \\ Microbiological investigation}

Several studies have provided further evidence that the overall sensitivity of blood and sputum cultures in CAP is low, particularly for patients with nonsevere CAP and no co-morbid disease and for those who have received antibiotic treatment before admission..$^{2-5}$ This has led to a changed recommendation that blood cultures may be omitted in a patient with no severity indicators or co-morbid disease providing the diagnosis of CAP has been definitely confirmed. The latter condition is important, particularly when dealing with a febrile patient where the site of infection is not clear and blood cultures can be very useful. The value of rapid legionella urine antigen testing was clearly demonstrated in a large outbreak of Legionnaires' disease in Holland, which found that early antibiotic management of patients could be guided by the results of rapid testing, resulting in improved outcome both in mortality and need for intensive care. ${ }^{6}$ Outside the epidemic situation there is also evidence that early detection of urine legionella antigen can positively influence management of sporadic cases of legionella pneumonia. ${ }^{7}$ This is an important message as there is growing evidence that delays in appropriate antibiotics adversely affect the outcome of pneumonia, particularly with legionella infection. Similarly, pneumococcal urine antigen tests have reported significantly greater sensitivity rates than routine blood or sputum cultures. ${ }^{89}$ Both legionella and pneumococcal urine antigen testing are recommended for severe pneumonia, together with a rapid reporting service for legionella urine antigen for all hospitals admitting patients with CAP. 


\section{Severity assessment}

Severity assessment remains the key to deciding the site of care (whether at home, in a medical ward, or critical care ward) and guiding both general management and antibiotic treatment. The severity assessment tool recommended in the 2001 BTS CAP guidelines ${ }^{1}$ was an amalgamation of aspects of the Fine pneumonia severity index (PSI), ${ }^{10}$ the modified BTS severity criteria described in the 1993 BTS CAP guidelines, ${ }^{11}$ and other adverse prognostic features published in the literature, and resulted in a rather cumbersome and non-memorable two step assessment process based on core, additional, and pre-existing adverse prognostic features. A recently published international study ${ }^{12}$ derived and tested a simpler severity assessment tool, the CURB-65 score, with a six point scale (0-5)-one point for each of Confusion, Urea $>7 \mathrm{mmol} / \mathrm{l}$, Respiratory rate $\geqslant 30 / \mathrm{min}$, low systolic $(<90 \mathrm{~mm} \mathrm{Hg})$ or diastolic $(\leqslant 60 \mathrm{~mm} \mathrm{Hg}$ ) Blood pressure, and age $\geqslant \mathbf{6 5}$ years-based on information available at the initial hospital assessment. Patients could be stratified into three groups according to increasing risk of mortality, hence adding support to clinical judgement regarding the need for hospital admission or intensive care management. Patients with a CURB-65 score of 3 or more are at high risk of death and should be managed as having severe pneumonia, those with a score of 2 are at some increased of risk of death and should be considered for short stay inpatient treatment or hospital supervised outpatient treatment, and those with a score of 0 or 1 are at low risk of death and may be suitable for home treatment. Both the BTS Pneumonia Guidelines Committee and the BTS Standards of Care Committee recommended adopting this revised severity assessment tool for the 2004 CAP update because of the more robust evidence, a single step assessment (compared with the current two step model), and a simpler algorithm to remember. Further prospective studies are needed to assess the true value of this newly adopted assessment tool, both in hospital and also in the community where a similarly predictive tool omitting the blood urea result (the CRB-65 score) can also be simply calculated.

\section{Use of non-invasive ventilation}

Non-invasive ventilation (NIV) plays a key role in the management of ventilatory failure in patients with chronic obstructive pulmonary disease, and several studies have reported that provision of NIV in patients with severe CAP can lead to initial improvement. ${ }^{13-15}$
However, as over half of these patients later deteriorate and require intubation, this has led to the recommendation that, for CAP, trials of NIV should only occur in an appropriate critical care setting. ${ }^{16}$

\section{Discharge planning}

A recent North American prospective multicentre study ${ }^{17}$ identified clinical factors that were useful in deciding whether a patient with CAP was sufficiently stable to be discharged from hospital. The presence of two or more features of clinical instability (based on temperature, heart rate, respiratory rate, blood pressure, oxygen saturation, mental status, and oral intake) predicted a significant chance of re-admission or mortality. It is recommended that this assessment is considered when planning for discharge.

\section{Antibiotics}

Moxifloxacin has joined levofloxacin as the only licensed newer fluoroquinolones recommended for CAP in the UK, although the use of moxifloxacin is limited as it is not licensed for use in severe pneumonia, nor is it available in a parenteral formulation in the UK. As before, new fluoroquinolones are not recommended as first line agents or for community use for pneumonia, but can provide a useful alternative in selected hospitalised patients with CAP. ${ }^{18} 19$

\section{FUTURE PRESENTATION OF GUIDELINE UPDATES}

Like the 2001 guidelines, the update does not cover economic or quality assessment of CAP care-an area which is becoming increasingly important for audit and clinical governance ${ }^{20}$ and will probably need to be included in future updates.

One challenge has been how to present updates of BTS guidelines. Various models are possible. In December the Infectious Diseases Society of America published the 2003 update of their 2000 guidelines on the management of CAP as a stand alone article on both their website and in Clinical Infectious Diseases ${ }^{21}$ - a table summarising both the recommendations of 2000 and also the new recommendations for 2003 (printed in bold). For this update the BTS is using a web based article linked to a pdf document of the full 2001 guidelines available from the BTS website. It is expected that readers will download and view both documents together, but feedback will be welcome to guide the BTS in the best way of presenting future updates for its numerous published clinical guidelines. Ultimately, dissemination of the guideline will require respiratory physicians to inform and educate their colleagues, both in hospital and primary care. It is hoped that these few important recommendations will be incorporated easily into clinical practice.

\section{ACKNOWLEDGEMENTS}

The authors thank the other members of the BTS Pneumonia Guidelines Committee for their hard work and enthusiasm in preparing the update: Dr T Boswell, Dr G Douglas, Professor R Finch, Dr W Holmes, Dr D Honeybourne, Dr Wei Shen Lim, Ms P Morley, Dr D Nathwani, Dr M Woodhead, Professor J Wyatt (declarations of interest are published at the end of the 2004 update document available on www.brit.thoracic.org. uk/guidelines); also to Jo Moon and Sheila Edwards for excellent help with preparing the update for presentation on the BTS website.

Thorax 2004:59:364-366.

doi: $10.1136 /$ thx.2004.024992

\section{Authors' affiliations}

J T Macfarlane, Chairman of the BTS Pneumonia Guidelines Committee, Nottingham City Hospital, Nottingham NG5 IPB, UK

D Boldy, Chairman of the BTS Standards of Care Committee, Pilgrim Hospital, Boston PE21 9QS, UK

Correspondence to: Dr J T Macfarlane, Nottingham City Hospital Nottingham NG5 1PB, UK; jmacfar1@ncht.trent.nhs.uk

\section{REFERENCES}

1 Macfarlane JT, Boswell T, Douglas G, et al. BTS guidelines for the management of community acquired pneumonia in adults. Thorax 2001;56(Suppl IV):iv1-64.

2 Theerthakarai R, El-Halees W, Javadpoor S, et al. Nonvalue of the initial microbiological studies in the management of nonsevere communityacquired pneumonia. Chest 2001;119:181-4.

3 Ewig S, Schlochtermeier M, Goke N, et al. Applying sputum as a diagnostic tool in pneumonia. Chest 2002;121:1486-92.

4 Waterer GW, Wunderink RG. The influence of the severity of community-acquired pneumonia on the usefulness of blood cultures. Respir Med 2001:95:78-82.

5 Campbell SG, Marrie TJ, Ansley R, et al. The contribution of blood cultures to the clinical management of adult patients admitted to the hospital with community-acquired pneumonia. Chest 2003; 123:1142-50.

6 Lettinga KD, Verbon V, Weverly GJ, et al. Legionnaires' disease at a Dutch flower show: prognostic factors and impact of therapy. Emerg Infect Dis 2002:8:1448-54

7 Lim WS, Macfarlane JT, Boswell TCJ, et al. Study of community acquired pneumonia aetiology (SCAPA) in adults admitted to hospital: implications for management guidelines. Thorax 2001;56:296-301.

8 Murdoch DR, Laing RTR, Mills GD, et al. Evaluation of a rapid immunochromatographic test for detection of Streptococcus pneumoniae antigen in urine samples from adults with community-acquired pneumonia. J Clin Microbiol 2001;39:3495-8.

9 Farina C, Arosio M, Vailati F, et al. Urinary detection of Streptococcus pneumoniae antigen for diagnosis of pneumonia. Microbiologica 2002;25:259-63.

10 Fine $M J$, Singer DE, Hanusa $B H$, et al. Validation of a pneumonia prognostic index using the MedisGroups Comparative Hospital Database. Am J Med 1993;94:153-9. 
11 British Thoracic Society. The British Thoracic Society guidelines for the management of communityacquired pneumonia in adults admitted to hospital. Br J Hosp Med 1993;49:346-50.

12 Lim WS, van der Eerden MM, Laing $R$, et al. Defining community acquired pneumonia severity on presentation to hospital: an international derivation and validation study. Thorax 2003:58:377-82.

13 Jolliet $P$, Abajo B, Pasquina $P$, et al. Non-invasive pressure support ventilation in severe communityacquired pneumonia. Intensive Care Med 2001;27:812-21.

14 Antonelli M, Conti J, Moro ML, et al. Predictors of failure of non-invasive positive pressure ventilation in patients with acute hypoxemic respiratory failure: a multi-centre study. Intensive Care Med 2001;27:1718-28.

15 Domenighetti G, Gayer R, Gentilini R. Noninvasive pressure support ventilation in nonCOPD patients with acute cardiogenic pulmonary edema and severe community-acquired pneumonia: acute effects and outcome. Intensive Care Med 2002;28:1226-32.

16 Kinnear W, Baudouin S, Blumenthal S, for the BTS Standards of Care Committee, et al. Non invasive ventilation in acute respiratory failure. Thorax 2002;57:192-211.

17 Halm EA, Fine MJ, Kapoor WN, et al. Instability on hospital discharge and the risk of adverse outcomes in patients with pneumonia. Arch Intern Med 2002; 162:1278-84.
18 Torres A, Muir JF, Corris P, et al. Effectiveness of oral moxifloxacin in standard first line therapy in community acquired pneumonia. Eur Respir $J$ 2003;21:135-43.

19 Salkind AR, Cuddy PG, Foxworth JW. Fluoroquinolone treatment of communityacquired pneumonia: a meta-analysis. Ann Pharmacother 2002;36:1938-43.

20 Barlow GD, Lamping DL, Davey PG, et al. Evaluation of outcomes in community acquired pneumonia: a guide for patients, physicians and policy makers. Lancet Infect Dis 2003:3:476-88.

21 Mandell LA, Bartlett JG, Dowell SF, et al. Update of practice guidelines for the management of community acquired pneumonia in immunocompetent adults. Clin Infect Dis 2003;37: 1405-33.

\section{LUNG ALERT}

\section{Obesity associated hypoventilation in medical patients is common, potentially dangerous and under-recognised}

$\Delta$ Nowbar S, Burkart KM, Gonzalez R, et al. Obesity-associated hypoventilation in hospitalized patients: prevalence, effects, and outcome. Am J Med 2004;116:1-7

$\mathrm{T}$ he authors studied consecutive severely obese patients $\left(B M I \geqslant 35 \mathrm{~kg} / \mathrm{m}^{2}\right.$ ) admitted to the medicine services of three teaching hospitals. Arterial blood gas tensions were measured to assess the prevalence, predictors, and outcomes of patients with obesity associated hypoventilation $(\mathrm{OAH})$, defined as $\mathrm{PaCO}_{2} \geqslant 43 \mathrm{~mm} \mathrm{Hg}$ and $\mathrm{pH} \leqslant 7.42$, with no other obvious cause of hypoventilation. Of 4332 consecutive admissions, 277 (6\%) had a BMI of $\geqslant 35 \mathrm{~kg} / \mathrm{m}^{2}$ and were screened. 127 were excluded for various reasons: 85 were unwilling to have an arterial blood gas measurement or could not provide consent, 32 used opiates, and 10 had a prior lung resection or a reduced $\mathrm{FEV}_{1} / \mathrm{FVC}$ ratio $(<50 \%)$.

Of the remaining 150 patients, OAH was found in $47(31 \%)$. Compared with severely obese patients without $\mathrm{OAH}$, patients with $\mathrm{OAH}$ were heavier, sleepier, more likely to have erythrocytosis, and had a lower FVC. They were more likely to require invasive mechanical ventilation $(6 \% v 0 \%)$ and to require discharge to a long term care facility ( $19 \% v 2 \%$ ). They also had a greater 18 month mortality rate $(23 \% v 9 \%)$ which persisted after controlling for a variety of potential confounders. Surprisingly, only $23 \%$ of patients $(n=11)$ were given a discharge diagnosis of $\mathrm{OAH}$, and only six of these were discharged with a recommendation to receive long term treatment (non-invasive nocturnal ventilation or tracheostomy).

In severely obese patients admitted to a medical service, $\mathrm{OAH}$ is common, associated with adverse outcomes, and under-appreciated. Clinicians should recognise the possibility of $\mathrm{OAH}$ in severely obese patients and consider performing arterial blood gas analysis.

N T Ayas

Assistant Professor of Medicine, University of British Columbia and the Centre of Clinical Epidemiology and Evaluation, Vancouver General Hospital, Vancouver, Canada; ayasnajib@pol.net 